\title{
Cross cultural leadership and the hospitality industry: a leadership style towards success in organizational goals in France
}

\begin{abstract}
The following paper is about cross-cultural leadership and its importance in the hospitality industry of France. The main objective of this paper is to identify critical literature about cross-cultural leadership and different types of leadership styles that exist in France, which will create awareness among organizations wanting to practice appropriate leadership styles for success in organizational goals. The whole paper has been divided into three parts. The first part of the paper is about the organizational and cultural issues that managers may encounter in France. The cultural organizational issues faced in France include ambiguous communication, inconsistency, and poor leadership. The second part of the paper analyzes the human obstacles that managers might face in new environments, and the appropriate theories to overcome these obstacles. The major human obstacles are senior management's resistance to change, stereotyping, lack of understanding, employees' suspicion about foreigners, nationalism, etc. The last part of the paper describes two appropriate leadership styles that managers may use in France. The two approaches are transactional leadership style and transformational leadership style. The current paper uses secondary data, specifically different literature such as research papers, articles, and book recommendations. This secondary data has been used to examine the importance of appropriate leadership styles for the hospitality industry of France. It aims to cover the appropriate leadership style for work efficiency, better performance, effective training, and development. It is understood that not all the organizations are equivalent in size, financial growth, management style, and most importantly may not be from the same geographical location. In a large country like France, every province may not follow the same culture. Thus, the recommended leadership styles may not be a true reflection for every organization, but an overall idea. To assess the most accurate leadership style for an organization, there is still a need for future research targeting organizational size, financial growth, management style, culture, and geographical location that must be taken into consideration.
\end{abstract}

Keywords: leadership, hospitality industry, culture, organization, employee

\section{Introduction}

Travel, tourism, and hospitality industries are among the fastest growing communities around the globe. In order to increase profits and see results, companies taking advantage of this trend will need detailed plans on how to conduct the travel and hospitality side of their business. Moreover, there must be programs about training skills for employees and managers, because they are one of the main components in offering tourism products to tourists. To do so, appropriate leadership styles should take place within the organization. One of the major challenges for the employees and managers of hospitality organizations, which are increasingly operating international businesses, is to interact and effectively work with people from different cultural environments. Many problems arise from intercultural communication between managers and employees, as well as between employees and hotel guests from different cultural backgrounds. Therefore, the issue of intercultural communication has recently had an increasing resurgence in the hospitality industry. Cultural awareness, sensitivity, and understanding of cultural differences should be perceived as a critical issue for business success. The importance of leadership to the success of a business cannot be over emphasized, as leadership is said to be a key factor for the success of any business. The hospitality industry is a service-oriented business that renders products and services to local and traveling guests. The hospitality business is seen as the people business. Because hospitality includes creating a welcoming environment for visitors, this business includes people in its day-to-
Volume 3 Issue I - 2019

\author{
Md Yusuf Hossein Khan \\ Assistant Professor, International University of Business \\ Agriculture and Technology, Bangladesh
}

\author{
Correspondence: Md Yusuf Hossein Khan, International \\ University of Business Agriculture and Technology, 4 \\ Embankment Drive Road, Uttara Model Town, Dhaka- 1230, \\ Bangladesh, Tel +880 I7798275 I0 \\ Email yusuf.hossein@iubat.edu
}

Received: May 22, 2018 | Published: January II, 2019 day operations. The hospitality industry is made up of businesses whose primary activities are the provision of accommodations, the selling of food, the sale of beverages for consumption on the premises, and the provision of entertainment. ${ }^{1}$ Different scholars have defined leadership in various ways and given many interpretations as to the meaning of leadership. Leadership is defined as an influence- that is, the art or process of influencing people so that they will strive willingly and enthusiastically toward the achievement of group goals. ${ }^{2}$ Another way of defining leadership, which has been aptly qualified as 'Managerial Leadership' sees it "as the process of directing and influencing the task related activities of group members. ${ }^{3}$ Another scholar, Cole ${ }^{4}$ conceptualized leadership as a dynamic process at work in a group whereby one individual, over a particular period and in a particular organizational context, influences the other group members to commit themselves freely to the achievement of group tasks or goal. Mullins ${ }^{5}$ defines leadership as the relationship through which one person influences the behavior or actions of other people. Based on these interpretations of what leadership is and means, the process of leadership cannot be separated from the activities of group and effective team building. The hospitality business cannot be successful without a good understanding of different leadership styles and how best to employ or apply them.

\section{Cross cultural leadership}

Cross cultural leadership is a term that describes how leaders work in the newly global marketplace. An international organization 
requires leaders who can adjust to various business environments quickly and interact easily with partners and employees from other cultures. A manager who is successful in their home country may not be as successful in the international arena. Cross cultural leadership is explained from two points of view (Giuliani and Kurson, 2002). One is from an organizational viewpoint, where cross-cultural leadership refers to the leader in the implementation of a business organization. This organization is constituted by employees of different nationalities, values, and various cultural backgrounds. From this viewpoint, crosscultural leadership can be seen in multinational companies. The second view regards cultural exchange and cultural changes; cultural leadership means adapting to a new wave of globalization. Here cross cultural leadership refers to a unique phenomenon to test the ability of a leader as to whether they are able to adapt and lead in cultural challenges. Multinational companies are prone to cultural variances; for this reason, their leaders must be knowledgeable about these cultural variances. Moreover, the nation's specific culture determines the leadership style. ${ }^{6}$ One of the areas of study currently popular among many researchers is leadership style, as it is still an attractive attribute about leadership among academics and managers. ${ }^{7}$ This attention to leadership style is relevant to subordinates, as they will often work more effectively and productively when their managers adopt a specific leadership style. ${ }^{8}$ Thus, within the leadership process, the style of leadership is very important. Managers develop their leadership style using appropriate education, training, and experience. ${ }^{9}$ Leadership is one of the most crucial social phenomena to examine, as it is so significant for the effectiveness of functions in both business and societal organizations. ${ }^{10}$ Autocratic leadership style is one of the most common and widely used leadership styles within the tourism and hospitality industry around the globe because of its unpredictable acceptance. This creates some difficulties in adopting the participative leadership style. There are deep roots of autocratic leadership style in the hospitality industry. ${ }^{7}$ Using different motivator factors and scheme managers in the hospitality industry can improve the job satisfaction of employees. ${ }^{8}$ Thus, to achieve an organizational goal, leadership styles work as an important tool to create motivated employees. ${ }^{11}$ Therefore, to improve guest services and employee job satisfaction, hospitality organizations should employ effective leadership. ${ }^{12}$ Organizations will be successful when their employees have a high level of job satisfaction. ${ }^{13}$

\section{Cross cultural leadership in the hospitality industry}

The term "culture" may have a variety of meanings when used in different contexts. ${ }^{14}$ Culture reflects beliefs, a way of life, and customs which are shared and accepted by people in a given society. Culture provides an individual with an awareness of their identity, roots, historical background, and a sense that one belongs to a certain community. ${ }^{15}$ It regulates and controls an individual's attitudes and behaviours. ${ }^{16}$ Culture is shaped by many forces, including religion, political power distribution, strong and charismatic leaders, historians and storytellers. ${ }^{17}$ Leadership skills are important for the hospitality industry because the hospitality industry has a dynamic environment, a service orientation, and a labour-intensive nature. ${ }^{18}$ Indeed, leadership style has a remarkable influence on employees' behaviour in the customer service industry, ${ }^{19,20}$ where leadership style focuses on the behaviour of the leaders rather than focusing on identifying personal characteristics of leaders. ${ }^{21}$ For instance, a transformational leadership style improves employee dedication, social behaviour, role clarity, and satisfaction..$^{22}$ Although different leadership styles can influence employees, we know little about the most appropriate leadership style in the restaurant industry. Problems may occur when people from different cultural backgrounds misunderstand each other, which results not only from language barriers but also cultural differences. Thus, it is important not only to speak a foreign language, but also to be aware of cultural differences which exist in different countries. ${ }^{15}$ Given the international nature of the hospitality industry, cultural awareness and intercultural communication have become very important in relations with hotel guests and hotel employees. There are several reasons why today's hotel professionals should be aware of these interactions and the possibilities of managing them. The importance of effective communication is well recognized today. Its role cannot be overemphasized in the hospitality setting, where improved communication has been identified as the key to quality, productivity, and competitiveness. ${ }^{23}$ "Dealing with people is one of the biggest challenges a manager has to face," and communication is often one of the most difficult areas. ${ }^{24}$ Miscommunication may strongly influence business effectiveness, including the loss of prestige and credibility, which ultimately leads to financial issues and other business problems. ${ }^{25}$ Literature indicates that $80 \%$ of a hospitality manager's time is spent communicating activities to hotel guests, peers, superiors and most frequently to subordinates. ${ }^{26}$

\section{Analysis and evaluation of organizational and national cultural issues}

\section{Organizational cultural issues}

Poor communication, ambiguity, and inconsistency are some prevalent organizational problems that a manager may face in a foreign country. These have a direct connection to a hostile and unpleasant workplace. These will make foreign workers less loyal, increasing harassment and high turnover of employees. ${ }^{27}$ All sizes of companies face the problem of poor communication while working abroad. In France, a manager may face problems communicating with employees. They may feel uncomfortable during communication of their company's goals, ideas, and suggestions. Another organizational culture issue that manager may encounter in France is ambiguity. Employees may not be clear on what their manager expects from them. Many hospitality chain groups operating in France are not originally based in France, and they may feel that the company's policies are in conflict with actual practices. Employees of French companies may say that this is not their company, it is a foreign chain. At that period, conflict may arise. Inconsistency is one of the organizational cultural issues. Assuming that the hospitality chain is from abroad, the French people may believe that the hotel policies are not applied fairly. For example, employees may expect that they will be punished if they cannot perform their work, but they also suspect that managers will not get punished for the same issues. They will not take it easily that some departments are enjoying more benefits in the same organization. Differences in priorities are other organizational culture problems. French employees may think that a hotel focuses too much on generating income, and that they are infringing on rights such as breaks and overtime or being pushed to work longer hours. These attitudes can lower employee performance and increase overall anger. Poor leadership is another organizational cultural issue. Employees of France may not respect the foreign manager and obey instruction if they think that the manager's leadership is inconsistent, weak and disreputable. This can contribute to organizational culture problems (Kippenberger, 2002).

\section{Hofstede's cultural dimension theory for France}

Power distance: Power distance is high in France. It is an aristocratic and wealthy country. This high-power distance means French people 
accept inequality. It refers to high class people always dominating lower class people. The government maintains and controls the strict laws and rules. The attitude towards managers is very much formal in France, and there is a hierarchy in terms of information flow. For example, if a poorly dressed person asks for directions, it is noticed that nobody comes to help him or her. It is a clear picture of power distance. $^{28}$

Individualism vs. collectivism: French people prefer individualism to collectivism and it means they take care of themselves rather than a group. They interrupt each other during discussions as though the argument is a form of entertainment. French people prefer contractbased work in the workplace. Their focus is on ensuring autonomy. Everyone can speak their opinion if they disagree with a situation or decision. Individuals in management prefer recognition of their individual effort rather than a team effort. France ranked 10th in position in individualistic countries. However, the most recent former collectivist president Hollade imposed a sizeable tax on the wealthy. So, it is expected that individualism will decline in the future (Tallman, 2013).

Masculinity vs femininity: France is a comparatively feminine country. In order to live, they focus more on work and quality of life. France has a welfare economy system. French people more rely on the government for welfare. There is no gender inequality in France. Every person is treated equally in France. Their main focus is on the performance and contribution of their citizen. It is less noticed that they have the attitude to become the best. The recent increase of female torture and rape is indicating that is absolutely not a feminist nation (Giuliani and Kurson, 2002).

Uncertainty avoidance: Uncertainty avoidance is high in France, which indicates that French people like clear rules and formal structural activities. The rules and regulations in France are comparatively strict in the case of business. To avoid any types of risk, strict regulations are incorporated into a company's charter. These activities also help to avoid illegal activity in business. ${ }^{28}$

\section{National cultural issues}

Language: French is the official language of France and $88 \%$ of the total population speaks in French. Other languages are not encouraged in France and about 3\% of the people use German. It is relatively difficult to find English speakers in France. Managers often face problems in communicating with employees who speak in French. So, a responsibility of the management will be to learn French as soon as possible. French people do not often feel comfortable speaking in other languages. ${ }^{29}$

Relationship and communication: French people emphasize courtesy and formal behavior. Trust is only developed through proper behavior. They are very strict about business, and they recognize a person's value based on their level of education and which part of the world the person comes from. A manager must learn some phrases in French at the very beginning of their time in the country because it will develop a good relationship with French people in the long run. Thus, the company will be able to sell products in the French market at a faster rate. ${ }^{30}$

Business meeting: In France, meeting are to be arranged at least 2 weeks in advance. Appointments are made through telephone or email depending upon whom you are going to meet. In July and August, no meetings are held in France because it is their vacation period. If any meeting is cancelled, immediately the manager has to phone and explain it. More importantly, no decision is made in a meeting; meetings are only for discussions, which is a totally different paradigm from many cultures.

\section{Analysis of major human obstacles: ways to overcome}

Stereotype: The tendency to stereotype is the most significant human obstacle to effective cross-cultural management. It means people make assumptions others based on their gender, race, age, ethnicity, nationality or socioeconomic status. Stereotypes are assumptions that are made about a people's character or attributes based on a common image of a specific group of people. People assume that a car will have four wheels, while a bicycle will have two wheels; likewise, people think that the attributes of men are different from those of women. But stereotyping about men and women will not be accurate all the time. When a company came to France and changed the organizational structure, the managers found the problem to be that French employees had a lack of urgency and were suspicious about foreigners.

Employee resistance: Managers at various levels resist change. The reason behind resistance is that management is not clear about the visibility of the change. Again, changes can come because of the lack of coherence in the mission and vision. After all, there is always a communication gap for organizational changes. ${ }^{31}$

Staff turnover: Staff turnover is high when changes happen. This is because they feel insecure about their job. If employees are not properly informed, they become suspicious about the new management, so there is a high probability of losing potential employees. People of some countries prefer nationalization to privatization. French people prefer nationalization because they believe that their jobs will be secure. So, for this company, it could be costly if these employees leave their jobs. A manager must act considering these concepts, or they will not be able to control these employees.

Judgmental attitudes: Managers abroad interact with a diverse range of people. Most of them want to believe that they are open-minded. Many of them feel discomfort with those who are different in behaviors, values, and beliefs. Then they evaluate those values, beliefs, and behaviors in a negative light. This is known as ethnocentrism, and it describes how we evaluate right and wrong based on values, behaviors, and ideas that are similar to our own. Managers must understand others from their perspective. French people tend to expect that a French person will be the manager. They may be concerned because they are not sure that the manager will try to fulfill their interests as well. ${ }^{31}$

Change leadership: Most recommend that leaders should emphasize shaping employees' attitudes and behaviors toward change. This change process can be seen in the areas like organizational development, justice, and decision-making participation. How leaders treat employees at the time of change has received the highest amount of attention and has been a powerful determinant of individuals' reactions to organizational change. There is a significant amount of overlap between researchers and practitioners' conclusions about effective change leadership behaviors. ${ }^{32}$ For example, communicating with individuals about the change and providing them with facilities for input are two of the most important elements in both the research and practitioners' recommendations for change leadership. Creating a transformational leadership style through empowerment, vision and, being serious about followers' needs are also key elements of their recommendations. 


\section{Overcome barriers to change}

The best way to overcome these barriers is to accept the differences of others from their perspective. French employees should be motivated to feel that the company will stay in France for a long period. The company should be aware of their interest as well.

Communication: French is the official language of France. The manager must learn French so that they can interact with the French employees and outline their company's ideas and goals. They will also be able to understand the manager's instructions.

Make employees the hero: A manager must convince French employees that they are an integral part of the organization and that their participation in decision-making will be appreciated in the future. They will need to be promoted based on performance. There will need to be no discrimination in wages. They will use all the facilities available under the French law. The company will provide all the necessary training to make them the hero of the company. As employees need to work 24 hours, shifting from single day work, the manager will convince them that they will be properly remunerated for their extra hours. ${ }^{29}$

Showing the potential of change: The manager will need to explain the potential of organizational changes to employees of all levels. The manager must show that these changes will not reduce their roles and responsibilities in the company. They will actively take part in the decision-making process for the interest of the company. For French subordinates, the manager will discuss the advantages of the organizational changes and show them that a newer culture will ensure a great prospective for them. Employees need not think that the company will not ensure a good work environment. The company has changed the organizational culture to increase productivity and improve operational performance. Good performance also means better remuneration is waiting for employees. ${ }^{31}$

\section{Identification and evaluation of two suitable leadership theories}

Leaders have a crucial role in accelerating organizational change and motivating people to achieve excellence at work by considering the pre-defined goals. Leaders set and administer the required strategies for driving continuous improvement in the prevailing processes, inspiring employees to superior performance and facilitating change across various departments of the company. ${ }^{33}$

\section{Transactional leadership}

Transactional leaders work based on the predefined modes of operation. They are more serious to ensure continuity in day-to-day operations, they ensure uninterrupted operations by setting up systems and processes, and they focus on the achievement of set targets. Such leaders maintain discipline in all activities and establish a systematic structure. They define a road map of action, make and implement policies, and inspire superior performance by a system of rewards and incentives. A transactional leader has no vision for acquiring market leadership in the future, but they are engaged in ensuring the assigned tasks are completed on a priority basis to meet the quality benchmark. The transactional leader works to satisfy the need at their level best according to Maslow's hierarchy of needs (Giuliani and Kurson, 2002). The manager will ensure rewards for good work or positive outcomes. They will focus on processes rather than forward-thinking ideas. So, this manager's focus will be on the contingent reward system or penalization. Contingent rewards are provided when employees do their specified task on time and ahead of time. These rewards are given them to motivate for working sincerely. If this is continued, they will be fired from the job according to the French labor law. Under this leadership, the role of manager will be vigilant about what subordinates are doing. If they do not work in compliance with the set goals, the manager will correct them immediately and monitor them properly. At the year end, the manager will take the responsibility for the work their subordinates are doing. ${ }^{34}$

\section{Transformational leadership}

Transformational leadership is a type of leadership in which the leader identifies the needed change, creates a vision to guide the change through inspiration, and executes the change with the commitment of the members of the group. For more understanding, transformation leadership is based on four components and these components can be described as Figure 2.

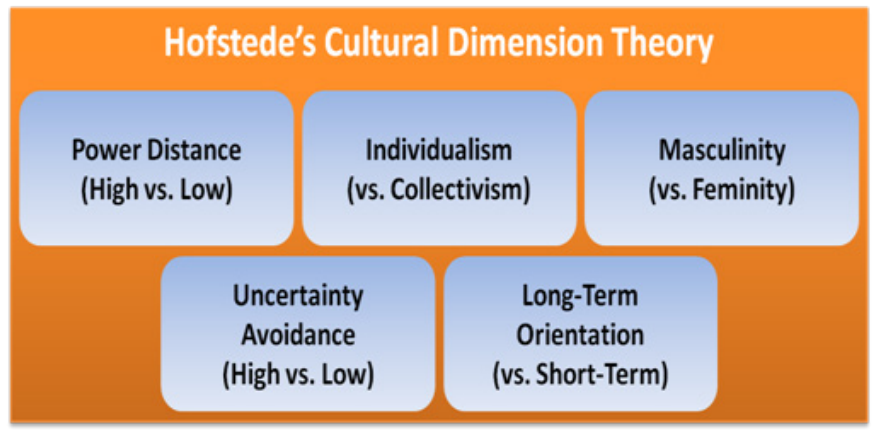

Figure I Hofstede's Cultural Dimension Theory Grint. ${ }^{27}$

\section{Transformational Leader}

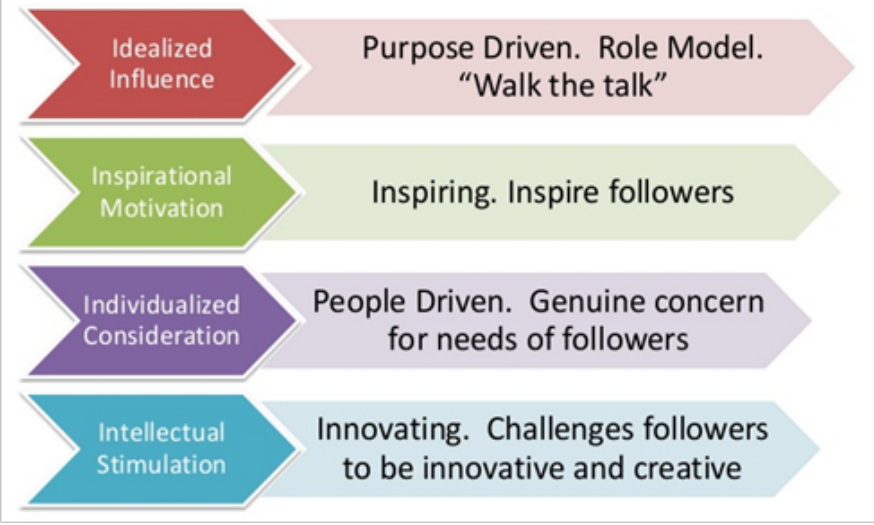

Figure 2 Transformational Leader.

Source, Guide

\section{Idealized influence}

Also known as charismatic leadership, transformational leaders act in ways that make them role models. Charismatic leaders are often willing to take a risk and lead the team from ahead. They can consistently be relied upon to do the right thing, displaying high moral and ethical standards. 


\section{Inspirational motivation}

The symbol of the term "team spirit" can be found from these types of leaders. Showing a high level of enthusiasm and optimism, providing both meaning and challenge to the work at hand, they try to achieve the organizational goal. They create an atmosphere of commitment to goals and a shared vision with the superiors and subordinates.

\section{Individualized consideration}

The best approach to transformational leadership is when leaders act as mentors and coaches. They respect the individual's desires and needs. Differences are accepted, and two-way communication is common. Transformational leaders are good listeners, and along with this comes personalized interaction. ${ }^{35}$

\section{Intellectual stimulation}

Avoiding public criticism, the transformational leader welcomes creativity and fosters an atmosphere in which their subordinates feel compelled to think about their old problems in an innovative way and find the best solution.

The real champions of any organizational change are transformational leaders. They are visionaries who can motivate others to achieve excellence in an organizational performance. Transformational leaders focus more on the development of cohesive teams and create an environment of collaboration for achieving the next level of better performance instead of completing the day-today organizational duties and tasks. More focus is given here on team building, alignment of individual specific goals, employee empowerment, and the creation of an innovative environment where employees will embrace organizational change positively. ${ }^{36}$ The manager will play the transformational leadership role in managing a business in France. Some key functions of a manager to become a transformational leader include:

- Create a vision: The manager will share and communicate their company's vision to all French employees so that they receive motivation for driving excellence at work.

- Building climate and culture: The manager builds a climate and culture of interdependence, flexibility, and mutuality. These are the major functions of any transformational leadership role. This organizational culture will inspire French employees to deliver performance excellence and achieve newer milestones at work (Giuliani and Kurson, 2002).

- External communication and liaising: For doing business, the manager keeps good relations with the external suppliers for the resource supply and technological assistance, and gains knowledge regarding the best used practices in the current business world. This quality strengthens the relationship with the desired stakeholders or organization partners. ${ }^{34}$

- Building a team or synergy: The manager emphasizes building a good team where every team member will be supportive. This will create a motivational climate and positivity in the workplace for completing works collaboratively.

- Talent search and development: As a transformational leader, the manager will take the responsibility to identify the best employee among all employees and nurture them properly via required training and development support. ${ }^{37-39}$

\section{Conclusion}

Cross-cultural leadership has become an important topic, as we are living in an era of globalization. Hospitality managers of multinational companies must know the key differences between cultures where they are running their businesses, particularly in France. Organizational and national cultural issues impact the performance of a company throughout the world. For this reason, a manager must be efficient enough to handle these cultural differences so that they can capitalize their resources. A transactional or transformational leadership strategy can be used by the manager to go through this difficult path. Among many leadership styles and variations in the culture, it may seem difficult to create a good system of operation management. But based on the discussion and the literature above, the transformational leadership seems to be more appropriate for the tourism and hospitality industry in France. Transformational leadership often tries to dig into problems and find better solutions for both employees and the organization. It's always crucial to know what type of leadership is better for making the business succeed, but also it is necessary to choose the management theory which will build the best relationship with your employees.

\section{Acknowledgements}

None.

\section{Conflict of interest}

Author declares that there is no conflict of interest.

\section{References}

1. Ofobruku SA, Kamoli MK, Amagbakhen OR. Geographical Information System Technology as a Decision Support for Hospitality Management. European Scientific Journal. 2012;8(23):38-64.

2. Koontz H, Weihrich H. Management-A Global Perspective. Japan: McGraw Hill Book Company; 1994.

3. Stoner JAF, Freeman RE, Gilbert DR. Management. 6th ed. New Delhi: Prentice -Hall of India; 2000

4. Cole GA. Personnel and Human Resources Management. 5th ed. London: Thomson Learning; 2005.

5. Mullins LJ. Management and Organisational Behaviour. 9th ed. Essex: Pearson Education limited; 2010.

6. Fisher-Yoshida B, Geller K. Transnational leadership development. 1st ed. New York: AMACOM; 2009.

7. Wood RC. Organizational Behaviour for Hospitality Management. 1st ed. Oxford: Butterworth- Heinemann Ltd; 1994.

8. Mullins LJ. Managing People in the Hospitality Industry. 3rd ed. Harlow: Addison Wesley Longman Limited; 1998.

9. Hersey P, Blanchard KH, Johnson DE. Management of Organizational Behavior: Leading Human Resources. 8th ed. New Jersey: Prentice-Hall Inc; 2008.

10. Antonakis J, Cianciolo AT, Sternberg RJ. The nature of Leadership. California: Sage Publications Inc; 2004

11. Kavanaugh RR, Ninemeier JD. Supervision in the Hospitality Industry. 3rd ed. The Educational Institute of the American Hotel \& Lodging Association. Michigan; 2001.

12. Woods RH, King JZ. Leadership and Management in the Hospitality Industry. 2nd ed. Educational Institute of the American Hotel \& Lodging Association, Michigan; 2002. 
13. Purcell J, Kinnie N, Hutchinson S, et al. Understanding the People and Performance Link: Unlocking the Black Box. London: CIPD; 2003. 104p.

14. Nicholls R. Customer-to-customer interaction (CCI): a cross-cultura perspective. International Journal of Contemporary Hospitality Management. 2011;23(2):209-223.

15. Luka I, Vaidesvarans S, Vinklere D. Educating Tourism Students for Work in a Multicul- tural Environment. Journal of Teaching in Travel \& Tourism. 2013.13(1):1-29.

16. Choi KH, Kim DY. A cross cultural study of antecedents on caree preparation behavior: Learning motivation, academic achievement, and career decision self-efficacy. Journal of Hospitality, Leisure, Sport \& Tourism Education. 2013;13:19-32.

17. Poprawski M. Leadership. An Intercultural Approach. Journal of Intercultural Management. 2009;1(1):28-41.

18. Gillet SR, Morda R. Effective leadership in tourism and hospitality organizations in the 21st century. In: S Kusluvan, editor. Managing Employee Attitudes and Behaviors in the Tourism and Hospitality Industry. New York: Nova Science Publishers; 2003. p. 599-630.

19. Ahmed I, Parasuraman A. Environmental and positional antecedents of management commitment to service quality: A conceptual framework. In: TA Swartz, DA Bowen, SW Brown, editors. Advances in services marketing and management. Greenwich, CT: JAI; 1994;3C:69-93.

20. Clark RA, Hartline MD, Jones KC. The effects of leadership style on hotel employees' commitment to service quality. Cornell Hospitality Quarterly. 2009;50(2):209-231.

21. Flaherty KE, Mowen JC, Brown TJ, et al. Leadership propensity and sales performance among sales personnel and managers in a specialty retail store setting. Journal of Personal Selling \& Sales Management. 2009;29(1):43-59.

22. Gill AS, Mathur N. Improving employee dedication and prosocial behavior. International Journal of Contemporary Hospitality Management. 2007;19(4):328-334.

23. Wolvin AD. Communication in the hospitality industry. International Journal of Hospitality Management. 1994;13(3):195-199.
24. Kavanagh S. Could you be a team leader? Travel Trade Gazette. 2002. 22p.

25. Łasiński G. Sztuka prezentacji, Poznań: Wyd; 2000.eMPI2.

26. Lolli J. Perceptions of the Importance and Preparedness of Interpersonal Communication Skills of the Entry-Level Hospitality Leader: Implications for Hospitality Educators. Journal of Teaching in Travel \& Tourism. 2013;13(4):354-373.

27. Grint K. Leadership. 1st ed. Houndmills, Basingstoke, Hampshire: Palgrave Macmillan; 2005.

28. Peterson M, Søndergaard M. Foundations of cross cultural management. 1st ed. Thousand Oaks, CA: Sage Publications; 2008.

29. Kessler E, Wong-MingJi D. Cultural mythology and global leadership. 1st ed. Cheltenham: Edward Elgar; 2009.

30. Livermore D. Leading with cultural intelligence. 1st ed. New York: American Management Association. 2010.

31. Moran R, Harris P, Moran S. Managing cultural differences. 1st ed. Burlington, MA: Butterworth-Heinemann; 2011.

32. Rowland D, Higgs M. Sustaining change. 1st ed. Chichester, England: Jossey-Bass; 2008.

33. Osborne C. Leadership. 1st ed. London: DK Pub; 2008.

34. Reynolds C. Women and school leadership. 1st ed. Albany: State University of New York Press; 2002.

35. Mindgarden. 2005-2013.

36. Sadler P. Leadership. 1st ed. London: Kogan Page Ltd; 2003.

37. Guide MS. 2013.

38. Harris P, Moran R. Managing cultural differences. 1st ed. Houston: Gulf Pub. Co; 2011.

39. Kaplan M. Cultural ergonomics. 1st ed. Amsterdam: Elsevier JAI; 2004. 